\title{
Transverse Dephasing Optimized Solid-State NMR Spectroscopy.
}

G. De Paëpe, N. Giraud, A. Lesage, P. Hodgkinson, ${ }^{\ddagger}$ A. Böckmann, ${ }^{\dagger}$ and L. Emsley. ${ }^{\star}$

Laboratoire de Chimie, UMR 5182 CNRS/ENS, Laboratoire de Recherche Conventionné du CEA (no. 23V), Ecole Normale Supérieure de Lyon, 69364 Lyon, France,

$\ddagger$ Department of Chemistry, University of Durham, South Road, Durham DH1 3LE, UK, and

$\dagger$ Institut de Biologie et de Chimie des Proteines, UMR 5086 CNRS, 69367 Lyon, France.

\section{Supplmentary Information.}

Parameters $a$ and $\square=1 / \square_{\mathrm{c}}$ for optimized eDROOPY decoupling schemes having the form $\square=$ $a \cos \left(\square_{c} t\right)$, obtained by optimizing the intensity of the $\square-{ }^{13} \mathrm{C}$ resonance in $\left[{ }^{13} \mathrm{C}-2\right]$-glycine for a range of spinning speeds and decoupling field amplitudes. The optimizations were carried out using the eDUMBO iterative approach described in[De Paëpe, 2003 \#1524] using the pulse sequence shown in figure $1 \mathrm{~b}$ with a $\square$ delay of $15 \mathrm{~ms}$. No special care was taken to synchronise the $\square$-pulse with the rotation or the decoupling sequence cycle time, especailly since the $\square$ periods represent over a hundred rotor periods. The optimisations were carried out on a Bruker Avance $500 \mathrm{MHz}$ spectrometer and the macro programs necessary are available on our website (http://www.ens-lyon.fr/STIM/NMR/) or upon request to the authors. As described in detail in,[De Paëpe, 2003 \#1524] it is likely that these parameters will work well on other spectrometers with similar probes, however the best method is to determine optimized parameters for each probe (in a similar manner to shimming). Once the parameters have been determined for a given probe using a model sample (for example we use $\left[{ }^{13} \mathrm{C}-2\right]$ glycine or L-isoleucine), these same parameters will not significantly change over time and will also work well for other samples of similar nature. There is no need to reoptimize the parameters of the pulse each time a spectrum is recorded.

Table 1. Parameters determined for a double-tuned 2.5mm CPMAS probe

\begin{tabular}{ccccc}
$\square_{1}(\mathrm{kHz})$ & $\square_{\mathrm{R}}(\mathrm{kHz})$ & $\mathrm{a}\left(^{\circ}\right)$ & $\square(\square \mathrm{s})$ & $\mathrm{T}_{2}{ }^{\circ}(\mathrm{ms})$ \\
\hline 150 & 30 & 31.7 & 6.26 & 95.4 \\
150 & 25 & 25.5 & 5.9 & 84.2 \\
150 & 20 & 24.5 & 6.2 & 55.8 \\
150 & 15 & 28.3 & 6.2 & 56.9 \\
150 & 10 & 32.2 & 6.2 & 76.6 \\
150 & 5 & 30 & 6.2 & 57.4 \\
100 & & & & \\
100 & 30 & 28.5 & 9.4 & 29.1 \\
100 & 25 & 35.0 & 9.63 & 22.9 \\
100 & 20 & 36.7 & 9.4 & 34.6 \\
100 & 15 & 42.0 & 9.43 & 29.2 \\
100 & 10 & 37.0 & 9.2 & 24.1 \\
\hline
\end{tabular}


Table 2. Parameters determined for a double-tuned 4mm CPMAS probe

\begin{tabular}{ccccc}
$\square_{1}(\mathrm{kHz})$ & $\square_{\mathrm{R}}(\mathrm{kHz})$ & $\mathrm{a}\left(^{\circ}\right)$ & $\square(\square \mathrm{s})$ & $\mathrm{T}_{2}{ }^{\prime}(\mathrm{ms})$ \\
\hline 100 & 12.5 & 33.5 & 9.1 & 60.8 \\
80 & 10 & 16.6 & 10.3 & 47.8 \\
75 & 10 & 18.3 & 11.6 & - \\
\hline
\end{tabular}

